\title{
Is the Army Hearing Conservation Programme Working in the Territorial Army?
}

\author{
Colonel C G Callow, \\ OBE, MB, MSc, MFCM, L/RAMC \\ Defence Medical Services Directorate Ministry of Defence, First Avenue House, High Holborn, LONDON WC1V 6HE
}

SUMMARY: This was a clinical and audiometric survey of a sample of 299 Territorial Army (TA) servicemen in the London area to identify the priority to be given to and the broad content of a Hearing Conservation Programme for the TA. A questionnaire was used to estimate previous noise exposure and the use of hearing protection. It is estimated that $4 \%$ of TA personnel have a hitherto undetected hearing loss which would result in their medical downgrading. Noise is likely to be responsible for three-quarters of such cases. For $86 \%$ of the sample TA service is the major source of hazardous noise. There is strong tendency for hearing loss to increase with length of TA service although it is not possible completely to disentangle the effects of age and social exposure.

\section{Introduction}

Over the years there have been several studies of Noise Induced Hearing Loss (NIHL) in the Regular Army $y^{1,2,3,4}$ which have determined the size and nature of the problem and have justified the Army Hearing Conservation Programme (AHCP). There are no similar data available for the Territorial Army (TA). The AHCP has not been fully implemented in the TA. Little is known about the auditory status of TA personnel because hearing is tested using the forced whisper test and not by audiometry ${ }^{5}$. It is therefore difficult to decide what priority should be given to AHCP in the TA and it is not clear whether the programme should be modified to meet the TA's specific requirements.

\section{History and Background}

That exposure to noise can cause deafness has been known since antiquity ${ }^{6}$; cases of hearing loss following exposure to firearms have been described since the 16th century 1 and occupational hearing loss in the 18th century $^{7}$. A distinction was made in 1831 between rupture of the tympanic membrane and deafness of gradual onset as a result of chronic exposure to loud noise $^{8}$. Fifty years later a causal link between the degree of noisiness of occupation and extent of resulting injury was established ${ }^{9}$. Much more recently the publication of a detailed report on hearing the noise in industry ${ }^{10}$ stimulated hearing protection programmes in industry and a survey of infantrymen in the mid $1960{ }^{2} \mathrm{~s}^{2}$ prompted the issue of V51R ear plugs to the Regular Army. Subsequently the AHCP was introduced. The introduction of the AHCP into the TA is incomplete. Although ear defenders are issued there is no formal health education programme and hearing assessments are carried out using the forced whisper test.

Weapons in use by both the TA and Regular Army produce high levels of noise (over 160dB) which, although of short duration (milliseconds), are very hazardous ${ }^{11}$. The current method of assessing hearing sensitivity in the TA does not detect the high frequency losses which are so characteristic of early NIHL ${ }^{12}$.
Screening audiometry is used as part of the routine series of medical examinations of regular soldiers; the technique is of proven value and offers a repeatable and quantitative method of measuring hearing ${ }^{13}$.

\section{Aim}

The aim of the study was to estimate mean hearing threshold levels of personnel of TA units based in London military district in order to identify the level of priority to be given to and the broad content of a TA Hearing Conservation Programme.

\section{Subjects and Method}

A clinical and audiometric survey of TA combat units based in the London area was carried out during the period November 1984-March 1985.

The drill halls of 12 battery, squadron or company sized sub-units were visited during drill nights. A random sample of 299 serving TA personnel (on the assumption that the prevalence of hearing deficit was $30 \%$, a sample of 300 would achieve a standard error of $2.5 \%$ ) completed a self-administered questionnaire under supervision. This was designed to identify types of and to estimate levels of military, occupational and social noise exposure. They were examined clinically to exclude obvious middle and outer-ear disease and underwent pure tone audiometry with semi-automatic, microprocessor controlled machines. Audiometers were calibrated at the start of the study, at approximately monthly intervals and at the conclusion of the study. Individual F Med 4's were scrutinised to ascertain currently assigned PULHHEEMS H degrees.

Data was processed using a CDC mainframe computer and the Statistical Package for Social Sciences ${ }^{14}$ was used for subsequent analyses.

\section{Results}

Questionnaires were administered to 302 subjects. Three were excluded from the study; 2 were ineligible, not being members of TA Group A units, and the third fell asleep during audiometry. The age distribution of the sample is shown at Table $1-71 \%$ were aged 29 or 
less and the distribution of length of TA service is at Table 2 . The bulk, $228(76.2 \%)$ were infantrymen, 46 $(15.3 \%)$ were artillerymen and $25(8.3 \%)$ were in an armoured unit. Fifty eight $(19.4 \%)$ admitted to exposure to loud noise in the 24 hours preceding examination; for 50 subjects the source was occupational although 5 described disco noise and 3 had fired their weapons.

Two hundred and sixty two $(87.6 \%)$ were in civilian employment and $34(11.4 \%)$ were unemployed. Of the former, only 3 could be confidently identified as having 'noisy' employment ${ }^{15}$. Forty three $(14 \%)$ had worked for more than 6 months in a place where shouting was necessary in order to be heard and $37(12.4 \%)$ indicated that they had worked for more than six months where hearing protection was provided.

One hundred and forty one $(47.2 \%)$ had fired weapons in a civilian setting; the commonest weapon was the shotgun and only 70 used hearing protection all or most of the time when firing outside a service environment.

There were 9 recruits who had no military noise exposure of any kind. The $7.62 \mathrm{~mm}$ Self Loading Rifle had $235(78.6 \%)$ users, the $9 \mathrm{~mm}$ Sub Machine Gun was used by $54(18 \%)$ and the pistol by $1(0.33 \%)$. Only 175

\section{Table 1 \\ Age Distribution of Sample}

\begin{tabular}{cccc}
\hline Age & $\begin{array}{c}\text { Absolute } \\
\text { Frequency }\end{array}$ & $\begin{array}{c}\text { Relative } \\
\text { Frequency \% }\end{array}$ & $\begin{array}{c}\text { Cumulative } \\
\text { Relative } \\
\text { Frequency \% }\end{array}$ \\
\hline$<20$ & 42 & 14.0 & 14.0 \\
$20-24$ & 96 & 32.1 & 46.2 \\
$25-29$ & 77 & 25.8 & 71.9 \\
$30-34$ & 36 & 12.0 & 83.9 \\
$35-39$ & 28 & 9.4 & 93.3 \\
$40-44$ & 14 & 4.7 & 98.0 \\
45 plus & 6 & 2.0 & 100.0 \\
\hline
\end{tabular}

Table 2

Frequency Distribution of Length of TA Service

\begin{tabular}{ccc}
\hline $\begin{array}{c}\text { TA Service } \\
\text { Length } \\
\text { (years) }\end{array}$ & $\begin{array}{c}\text { Absolute } \\
\text { Frequency }\end{array}$ & $\begin{array}{c}\text { Relative } \\
\text { Frequency \% }\end{array}$ \\
\hline-1 & 89 & 29.8 \\
-5 & 120 & 40.1 \\
-10 & 54 & 18.0 \\
-15 & 14 & 4.7 \\
$15+$ & 22 & 7.4 \\
\hline Totals & $\mathbf{2 9 9}$ & $\mathbf{1 0 0 . 0}$ \\
\hline
\end{tabular}

Table 3

Use of Hearing Protection when Firing

Personal Weapon

\begin{tabular}{|c|c|c|}
\hline Reply & Frequency & $(\%)$ \\
\hline$\overline{\text { Never fired }}$ & 9 & $(3.0)$ \\
\hline Always & 175 & $(58.5)$ \\
\hline Most of the time & 75 & $(25.1)$ \\
\hline Some of the time & 32 & $(10.7)$ \\
\hline Never & 8 & $(2.7)$ \\
\hline
\end{tabular}

$(58.5 \%)$ of firers stated that they always used eap defenders when firing their personal weapon. Table 3 summarises admitted hearing protection use firing personal weapons.

One hundred and seventy nine $(59.9 \%)$ had bee? exposed to heavy weapon noise such as mortars, antie. tank weapons, artillery or armoured vehicle maing armament. Sixty six ( $36 \%$ of those exposed) admitted to' not always using hearing protection. A summary of heavy weapon noise exposure and associated use o오 hearing protection is at Table 4 .

On otoscopy and clinical examination there were subjects in whom there were signs or symptoms. conditions which might affect hearing thresholds. 무 summary of the findings is at Table 5.

Valid audiograms were obtained for 299 subjects. Th: mean hearing thresholds for the whole sample ore illustrated at Figure 1 and the relative frequex distribution of the $3,4 \& 6 \mathrm{kHz}$ averages are showriato Figure 2. There were $34(11.4 \%)$ left ears and 320 $(10.5 \%)$ right ears found to have a deficit of $30 \mathrm{~dB}-0$ more of the $3,4 \& 6 \mathrm{kHz}$ average; estimated standa errors and 95\% confidence intervals for these prevalence rates are shown in Table 6 . The difference between the prevalence rates for the left and right ears i not statistically significant ( $\mathrm{p}>0.3$ ). Subsequent scrutin of audiograms of those in whom a clinical abnormalit had been noted revealed 59 normal audiograms, 25 abnormal and suggestive of NIHL alone and 47 that were abnormal but suggested conditions other than NIHL.

There were $287(96 \%)$ left ears with an $\mathrm{H}$ grading of or 2. This figure was the same for right ears although here a grading of 1 was more frequent. The frequenc $\$$ distribution of PULHHEEMS $\mathrm{H}$ categories is shown Table 7.

Scrutiny of medical documents of 290 subjects (重. recruits had yet to be examined by their $\mathrm{RMO}$ ) found aB to be $\mathrm{H} 2$ or above with $244(84.1 \%$ ) shown as $\mathrm{H} 2$ in bot ears and $46(15.9 \%)$ as $\mathrm{H} 1$ in both.

\section{Discussion}

The age structure of the sample does not diffe significantly from that of all TA Group A units; $29.8 \%$ have less than 1 years service (the figure often quoted 
Table 4

Summary of Heavy Weapon Noise Exposure

Numbers of Different Heavy Weapons Fired

\begin{tabular}{|c|c|c|c|c|c|c|c|c|}
\hline $\begin{array}{l}\text { Types of heavy weapon fired } \\
\text { Frequency }\end{array}$ & & $\begin{array}{c}0 \\
120\end{array}$ & $\begin{array}{c}1 \\
106\end{array}$ & $\begin{array}{c}2 \\
34\end{array}$ & $\begin{array}{c}3 \\
23\end{array}$ & $\begin{array}{c}4 \\
10\end{array}$ & $\begin{array}{l}5 \\
4\end{array}$ & $\begin{array}{l}6 \\
2\end{array}$ \\
\hline \multicolumn{3}{|c|}{ Ranking of Heavy Weapons by Number of Responses } & \multicolumn{6}{|c|}{ Use of Hearing Protection with Heavy Weapons } \\
\hline Weapon & Responses & & Reply & & & & Fre & ncy $(\%)$ \\
\hline Shoulder launched Anti-tank & 134 & & Always & & & & 113 & $(63.3)$ \\
\hline Any artillery & 57 & & Most of $t$ & me & & & 37 & (20.6) \\
\hline Mortars & 40 & & Some of & ime & & & 20 & (11.1) \\
\hline Large calibre machine gun & 36 & & Never & & & & 7 & $(5.0)$ \\
\hline Towed anti tank weapon & 26 & & & & & & & \\
\hline Armoured vehicle main gun & 22 & & & & & & & \\
\hline
\end{tabular}

for the TA as a whole is $30 \%$ ) and all were members of combat units. Were it not for the high prevalence of upper respiratory tract infection the findings of this survey could be safely generalised to combat units of the TA as a whole. The contribution that occupational exposure makes to overall noise dose in the TA has probably been under-estimated because of the relatively few found to have noisy employment (in the Midlands, for example, this proportion could reasonably be expected to be higher).

No statistically significant difference could be demonstrated between the $3,4 \& 6 \mathrm{kHz}$ averages of those admitting to exposure to loud noise in the

\section{_Leftear Right ear}

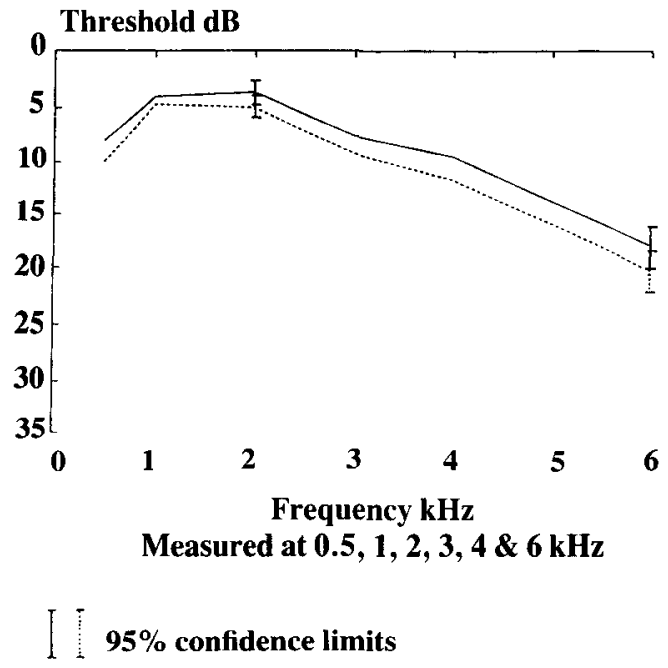

Fig. 1 Mean hearing threshold Whole sample, $n=299$
Table 5

Summary of Findings on Clinical Examination/Otoscopy

\begin{tabular}{lcc}
\hline Finding & $\begin{array}{c}\text { Number of } \\
\text { subjects }\end{array}$ & $\begin{array}{c}\text { \% of whole } \\
\text { sample }\end{array}$ \\
\hline History of coryza & 62 & 20.7 \\
Wax & 53 & 17.7 \\
Scarring of TM & 11 & 3.7 \\
Middle ear fluid & 2 & 0.7 \\
Complained of tinnitus & 2 & 0.7 \\
Perforation TM & 1 & 0.3 \\
\hline Totals & $\mathbf{1 3 1}$ & $\mathbf{4 3 . 8}$ \\
\hline
\end{tabular}

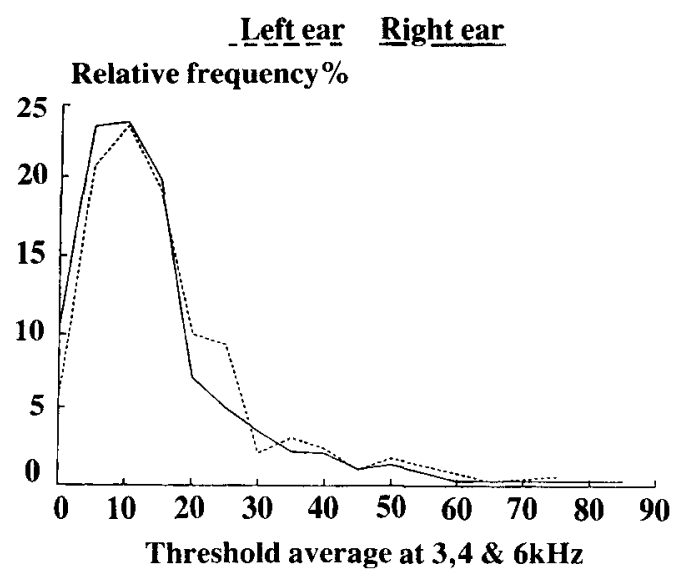

Fig. 2. Distribution of threshold averages, $d B$ at $3,4 \& 6$ $\mathrm{kHz}$, whole sample $\mathrm{n}=299$ 
preceding 24 hours and those who did not. These subjects were therefore not subsequently excluded from analyses. The proportion of subjects admitting to loud noise would have implications for any routine audiometry programme in the TA. Of the 58 who might have demonstrated a noise-induced temporary threshold shift, 50 had been exposed to noise at work. It might not be practicable to insist that TA soldiers limit occupational noise exposure before audiometry - it is suggested that only those found to be $\mathrm{H3}$, or worse, by routine audiometry would need repeat audiometry following a gap of 24 hours after last exposure to loud noise.

Table 8 shows an increasing level of hearing threshold with TA service length; the differences in each ear are statistically significant. It would be unwise to suggest that these changes were due to TA service alone but, given that the predicted change in $3,4 \& 6 \mathrm{kHz}$ average at age 45 is only $7 \mathrm{~dB}$ (using the method described by Robinson ${ }^{16}$ which now has limitations because it was developed before the advent of the loud disco and personal stereos) and the relatively few subjects with occupational noise exposure, TA service must represent an important source of hazardous noise.

Answers to questions relating to the use of ear defenders when firing weapons in both civilian and military settings have implications for the health education content of AHCP in the TA. Under $60 \%$ said they always used hearing protection when firing their personal weapons and the response was little better for those who had fired support or heavy weapons. It is clear that the use of hearing protection is by no means universal in the TA.

The large number (131) of subjects found to have signs or symptoms of conditions which might have affected hearing thresholds was of some concern. These audio-

Table 6

Prevalence of $3,4 \& 6 \mathrm{kHz}$ average of $30 \mathrm{~dB}$ loss or more

\begin{tabular}{lccc}
\hline Ear & Prevalence \% & $\begin{array}{c}\text { Estimated } \\
\text { Standard Error }\end{array}$ & $\begin{array}{c}\mathbf{9 5} \text { Confidence } \\
\text { Interval }\end{array}$ \\
\hline Left & 11.4 & $1.8 \%$ & $7.8 \%$ to $15 \%$ \\
Right & 10.5 & $1.8 \%$ & $7.0 \%$ to $14 \%$ \\
\hline
\end{tabular}

Table 7

Absolute and (relative \%) frequency distribution of PULHHEEMS H grading after audiometry

\begin{tabular}{lcccc}
\hline $\begin{array}{l}\text { H Category/ } \\
\text { Ear }\end{array}$ & 1 & 2 & 3 & $4 / 8$ \\
\hline Left & $202(67.6)$ & $85(28.4)$ & $10(3.3)$ & $2(0.7)$ \\
Right & $228(76.3)$ & $59(19.7)$ & $11(3.7)$ & $1(0.3)$ \\
\hline
\end{tabular}

grams were scrutinised - 59 were normal, 25 hasid audiograms suggestive of NIHL and 47 audiograms were suggestive of conductive deafness. Of this latter grou there were only 10 left and 10 right ears with a $3,4 \& 8$ $\mathrm{kHz}$ average of greater than $30 \mathrm{~dB}$; all were graded $\mathrm{HP}$ or $\mathrm{H} 2$ except 2 left and 3 right ears which were $\mathrm{H} 3$. may therefore be concluded that although $35 \%$ of those found to have a clinical abnormality were subsequent demonstrated to have associated audiometric abnos malities, few would have been graded below $\mathrm{H} 2$ as result. In other words it is suggested that up to $4 \%$ of personnel of TA independent units might have hitherto undetected hearing loss which would make them $\mathrm{H} 3$ or worse; NIHL is likely to be responsible fơt at least $75 \%$ of such cases.

Comparison with other military studies might help tiे put the audiometric findings of this study infer perspective and allow at least a general conclusion to drawn about the audiometric status of the sample. The most recent available data on Regular Army units are those assembled by Brown in his study of NIHL suso tained during the Falklands war ${ }^{17}$. He used results of routine audiometry before the campaign as a starting point and these are used in Table 9 to compare qhe relative frequency distribution of PULHHEEM\$ gradings with this study. No statistically significant difference can be demonstrated between the fror portions of $\mathrm{H}$ gradings in the 2 groups. Figur compares the frequency distribution of 3,4 \& 6 他 averages of Brown's pre-Falkland sample with sample. The frequency distributions are very similar annt no statistically significant difference can be dempige strated between the proportions found by each stity with the same threshold averages. It has not boe. possible to standardise these data for length of service of age but it is still worrying that a sample with such a hig proportion of soldiers with less than 1 year's service hos an auditory status so close to comparable regula soldiers.

\section{Table 8}

\section{$3,4 \& 6 \mathrm{kHz}$ averages by TA service length}

\begin{tabular}{|c|c|c|c|}
\hline $\begin{array}{l}\text { Length of } \\
\text { TA service } \\
\text { (years) }\end{array}$ & $\begin{array}{l}\text { Left } \\
\text { ear }\end{array}$ & $\begin{array}{c}\text { Right } \\
\text { ear }\end{array}$ & $\mathbf{n}$ \\
\hline $\begin{array}{l}<1 \\
1-5 \\
6-10 \\
11-15 \\
\text { over } 15\end{array}$ & $\begin{array}{l}9.97 \\
12.95 \\
15.39 \\
18.5 \\
26.86\end{array}$ & $\begin{array}{c}7.79 \\
11.40 \\
13.80 \\
18.79 \\
20.23\end{array}$ & $\begin{array}{c}89 \\
120 \\
54 \\
14 \\
22\end{array}$ \\
\hline & $\begin{array}{c}F=10.61 \\
P<.0001 \\
d f=4\end{array}$ & $\begin{array}{c}\mathrm{F}=7.42 \\
\mathrm{P}<.0001 \\
\mathrm{df}=4\end{array}$ & \\
\hline
\end{tabular}




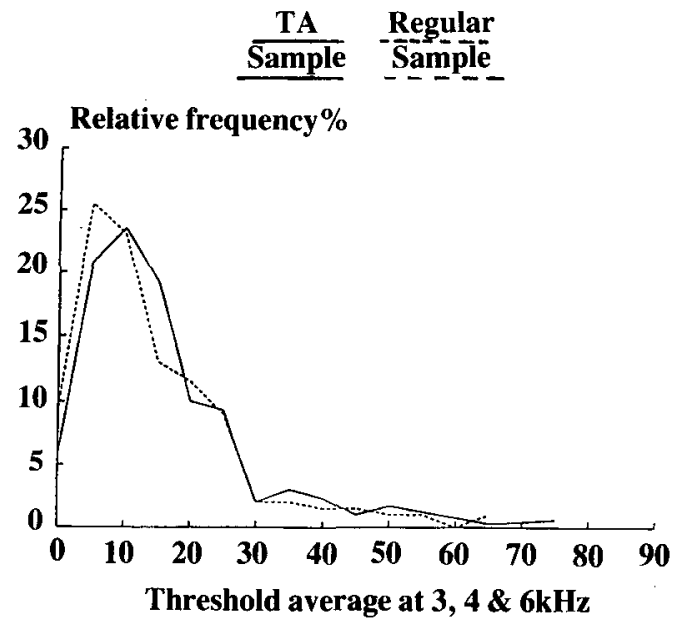

Left ear

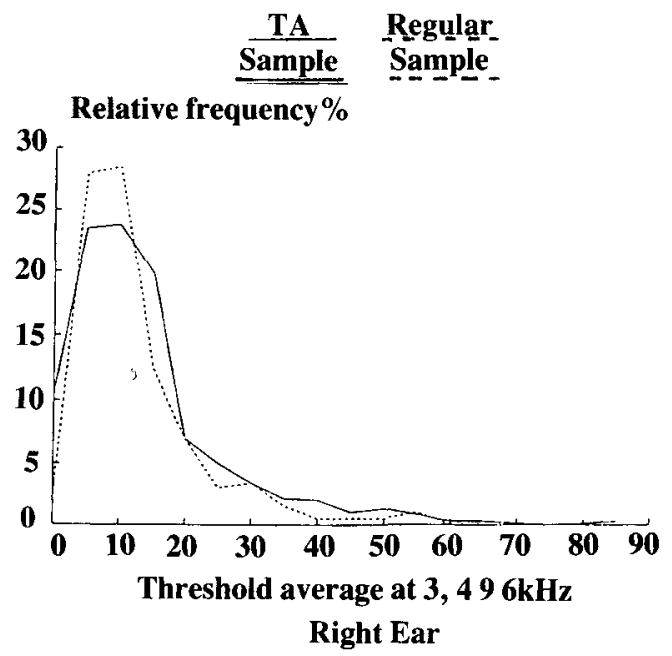

Fig. 3. Comparison of $3,4 \& 6 \mathrm{kHz}$ averages with a sample of regular soldiers ${ }^{16}$

Table 9

Comparison of relative frequency distribution of PULHHEEMS H grading with regular soldiers pre-Falklands ${ }^{17}$.

\begin{tabular}{ccc}
\hline $\begin{array}{c}\text { Hgrade } \\
\text { Worst ear }\end{array}$ & $\begin{array}{c}\text { Regular pre- } \\
\text { Falklands } \\
(\mathbf{n = 2 0 5})\end{array}$ & $\begin{array}{c}\text { This } \\
\text { study } \\
(\mathbf{n = 2 9 9})\end{array}$ \\
\hline 1 & 58.0 & 60.9 \\
2 & 31.2 & 31.4 \\
3 & 10.2 & 7.0 \\
$4 / 8$ & 0.4 & 0.6 \\
\hline
\end{tabular}

\section{Conclusions}

It is estimated that up to $4 \%$ of personnel of TA independent units might have a hitherto undetected hearing loss which would make their PULHHEEMS grading $\mathbf{H 3}$ or worse. NIHL is likely to be responsible for $75 \%$ of such cases, and TA service represents an important source of hazardous noise.

Comparison with studies of the Regular Army suggests that the auditory status of independent TA combat units is similar to their regular counterparts whereas it could reasonably be expected to be better. AHCP is not working in the TA. It should be fully implemented and the use of hearing protection when firing weapons must be enforced and audiometry must be introduced.
The associated health education programme should be amended to reflect the different circumstances in the TA.

\section{Acknowledgements}

I am indebted to those staff of APRE whose help and advice made the survey possible. I must also thank Brigadier David Worsley, Colonel Tony Harwood and Doctor Hugh Sanderson for their advice, encouragement and patience.

\section{REFERENCES}

1. MOORE D A. A review of the nature and problem of impulse noise damage to the soldiers hearing and its prevention. J R Army Med Corps 1976; 122: 158-169.

2. LIVESEY B. Acoustic trauma as an occupational hazard of infrantrymen. J R Army Med Corps 1965; 111: 188-193.

3. COOMBE D H. The implications of the Army's audiometric screening programme. Part 1 - Accoustic trauma amongst serving infantry personnel. J R Army Med Corps 1980; 126: 18-24.

4. CoOMBE D H. The implications of the Army's audiometric screening programme. Part $2-$ Hearing acuity in British Army recruits. J R Army Med Corps 1980; 126: 25-32.

5. PulhHeEms administrative pamphlet 1972. Army code No 13371.

6. KING P F. Hearing conservation in the Royal Air Force. $J$ $R$ Soc Med 1978; 72: 562-573.

7. RAMAZZINNi B. A treatise on the diseases of tradesmen. London 1705.

8. FOSBROKE J. Practical observations on the pathology and treatment of deafness. No. 11 Lancet 1831 ; 19: 645-648. 
9. BARR T. Enquiry into the effects of loud sounds upon the hearing of boilermakers and others who work amid noisy surroundings. Proc Phil Soc Glasgow 1886; 17: 223-239.

10. BurNs $W$ and RoBinson $D$ W. Hearing and noise in industry. London: HMSO 1970.

11. Elwood M A, Brasher P F and Croton L M. The effects of noise on hearing: Part 1 weapon noise. Farnborough Hants. Army Personnel Research Establishment, 1973. Report APRE 39/73 (R).

12. Rai R M, Chaturvedi $\mathbf{R} \mathrm{C}$ and Ranganathan $\mathrm{S}$. Audiometric survey in Army recruits. Armed Forces Med J of India 1974; 30: 146-149.

13. CABlE $H R$ and MORRIS T M O. The grading of hearing loss. J R Army Med Corps 1971; 117: 3-8.
14. NIE N H, et al Statistical Package for the Social Sciences. 2nd Ed. New York: McGraw Hill, 1975.

15. Henwoon W R. Problems associated with occupational $\frac{\widehat{\Phi}}{\mathrm{Q}}$ deafness as a prescribed disease. Health Trends $1982 ; 14:$ 76-78.

16. RoBinson D W. Relations between hearing loss and noise응 exposure. In: Burns W, Robinson D W. Hearing and noise? in industry. London: HMSO 1970; 100-151.

17. BROWN J R. Noise induced hearing loss sustained during $\stackrel{\mathcal{F}}{\sim}$ land operations in the Falkland Islands campaign 1982. $J$ Soc Occup Med 1985; 35(2): 44-54.

\section{MILITARY HOSPITAL FOR HEAD INJURIES 1913-1945}

On Monday 6 June, 1988, the Anniversary of D-Day, the Chancellor of the University of Oxford will unveil a plaque to commemorate the use of St. Hughs College, Oxford as the Military Hospital for Head Injuries. It is hoped that patients who were treated and medical and ancillary staff who served at St. Hughes during this time will come to the ceremony.

Further enquiries should be addressed to Professor P.M. Daniel at the Royal College of Surgeons of England. 